\title{
Benchmark Test of CFD Software Packages for Sunroof Buffeting in Hyundai Simplified Model
} 차량 썬루프 버페팅 현상에 대한 전산 해석 소프트웨어의 예측 성능 벤치마크 연구

\author{
Munhwan Cho*, Chisung Oh*, HyoungGun Kim* and Kang-duck $\mathrm{Ih}^{\dagger}$ \\ 조 문 환.오 치 성.김 형 건.이 강 덕
}

(Received December 17, 2013 ; Revised January 22, 2014 ; Accepted January 22, 2014)

Key Words : Sunroof Buffeting(썬루프 버페팅), Benchmark(벤치마크), Aeroacoustic(공력소음), Hyundai Simplified Model(현대단순차량모델), Acoustic Response Test(음향응답실험)

\begin{abstract}
Sunroof buffeting is one of the most critical issues in the vehicle wind noise phenomena. The experimental approach to solve this issue typically requires a lot of time and resources. To reduce time and cost, the numerical approach could be taken, which can also privide more insights into physical phenomena involved in sunroof buffeting, only if the accuracy in its predictions are guranteed. The benchmark test of various numerical solvers is carried out for the buffeting behavior of a simplified vehicle body, the Hyundai simplified model(HSM). The results of each solver are compared to the experimental measurements in a Hyundai aeroacoustic wind tunnel(HAWT) at various wind speeds. In particular, acoustic response tests were performed and the results were provided prior to all simulations in order to consider the real world effects that could introduce discrepancies between the numerical and experimental approaches. Through this study, most solvers can demonstrate an acceptable accuracy level for actual commercial development and high precision experimental data and computational prediction priories can be shared in order to promote the numerical accuracy level of each numerical solver.
\end{abstract}

\section{요 약}

썬루프 버페팅 현상은 차량 주행시 발생하는 주요 바람소리 문제점 중 하나이다. 버페팅 문 제점을 해결하기 위해서 전산 해석을 적용한다면, 실험적 방법보다 비용을 절감할 뿐 아니라 발 생 원리 또한 규명할 수 있다. 그러나 전산 해석을 이용하기 위해서는 해석 결과의 정확성이 보 장되어야 실제 차량 개발에 적용할 수 있다. 이 연구에서는 해석적 방법의 정확도 향상을 위해 주요 상업용 전산해석 소프트웨어들의 썬루프 버페팅 현상 예측에 대한 벤치마크 테스트를 수 행하였다. 해석 대상은 차량의 형상을 간략하게 만든 HSM(Hyundai simplified model)을 이용하였 고, 정확도 비교를 위해 속도별 버페팅 현상에 대한 실험을 현대자동차 공력무향풍동에서 실차

† Corresponding Author; Member, Hyundai Motor Group E-mail : baramsolee@hyundai.com Tel : +82-31-368-6461

* NVH Research Lab 1, Hyundai Motor Group
\# A part of this paper was presented at the KSNVE 2012 Annual Autumn Conference

\$ Recommended by Editor-in-Chief Weuibong Jung

(c) The Korean Society for Noise and Vibration Engineering 
내부의 흡음재에 의한 효과를 해석적으로 고려하기 위해 음향 응답 실험을 수행하여 해석 결과 정확도 향상을 위해 각 상용 소프트웨어 제작사에 해석 전에 제공 하였다. 이 연구를 통해 대부 분의 상용 소프트웨어들이 실험결과와 유사한 해석 결과를 도출하였다. 또한, 실제 차량 개발에 서 적용하기 위한 해석 예측 우선순위를 서로 공유하여 추가 해석을 통해 차량 개발에 적용 가 능한 보다 정밀한 해석 정확도를 얻어낼 수 있었다.

\section{Nomenclature}

$c$ : Speed of sound

ctf : Complex transfer function

$F \quad$ : Fourier transform of $f$

$f$ : Signal of reference microphone

$G$ : Fourier transform of $g$

$g$ : Signal of response microphone

$H$ : Total complex transfer function

$L \quad$ : Neck length

$S$ : Neck area

$V \quad$ : Cavity volume

* : Complex conjugate

\section{Introduction}

The buffeting phenomenon is considered one of the most important issues of wind noise problems. It is very difficult to apply the numerical approach because of the strong coupling between aerodynamic behavior and aeroacoustic propagation. The real world effects of actual vehicle driving conditions can particularly highlight the differences between the numerical method and experimental results. These are challenging obstacles when the numerical approach is applied to the commercial vehicle development process.

One of the real world effects is leakage flow from the vehicle body as shown in Fig. 1(a). Additional flow is made by pressure differences between interior and exterior parts of the driving vehicle. This auxiliary flow can affect the shear layer at the trailing edge of the sunroof opening. Moreover, sound absorption material inside a car can make a damping effect to change the charac- teristics of buffeting as depicted in Fig. 1(b). It is very important to consider the damping effect, which can affect the shear layers on the sunroof opening area, since a ground vehicle has a lot of sound absorption material such as seats, trim covers and floor carpets. In addition, elastic deformations of vehicle body panels through strong resonance, which is referred to as the compliance effect is shown in Fig. 1(c).

These effects should be taken into consideration to progress the accuracy and effectiveness of the numerical methodologies that are required in the road vehicle development process. Besides these

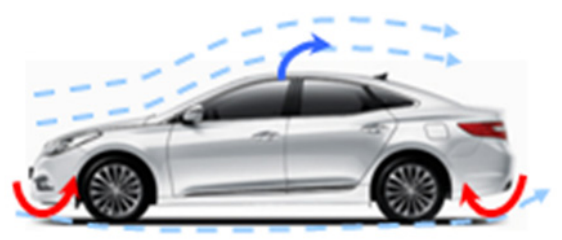

(a) Leakage effect

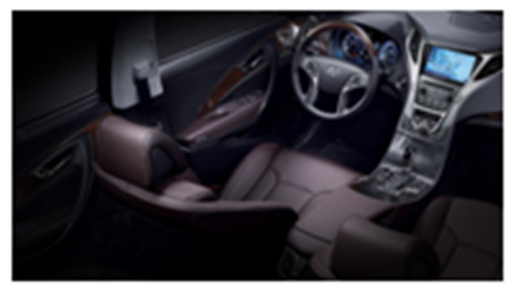

(b) Damping effect

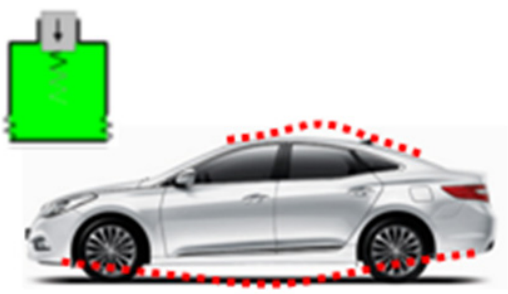

(c) Compliance effect

Fig. 1 Real world effects 
effects, the accuracy issues in the actual development process can be caused by constraints of computational resources. The fully extensive simulation of turbulent flow around an entire car is nearly impossible, because it requires tremendous computational resources. However, it is not actually necessary to predict all properties at every single frequency range in the practical development process. For example, in a simulation of sunroof buffeting, only a peak frequency in which maximum sound pressure occurs is important. Outside the resonance area, it is not of interest and some errors can be acceptable in the practical development process. For the efficiency and accuracy of the numerical approach, computational prediction priority should be decided between $\mathrm{S} / \mathrm{W}$ providers and commercial users.

In order to overcome these accuracy and efficiency issues, an open benchmark study about the buffeting phenomena was conducted with several CFD solvers. Seven pieces of worldwide commercial software containing major solvers and prototype codes under construction were in attendance for this study. The primary objective of the benchmark test was to predict buffeting frequencies and sound pressure levels at various wind speeds. Computational prediction priorities for the buffeting phenomena can be proposed to improve the efficiency of the simulation. It is assumed that only the damping effect is considered out of the real world effects. In order to apply the damping effect to the simulation, an acoustic response test (ART) was conducted. The results of ART, geometries of the simplified vehicle model and experimental conditions were provided as preliminary data for each numerical study.

\section{Experimental Results}

\subsection{Experimental Setup}

The upper part of a conventional road vehicle body can be simplified to a wedge-like shape for numerical and experimental studies. A Hyundai simple model(HSM) is deviced to reproduce complex vortex structures at important parts of a vehicle including the wind shield glass, roof, A-pillars and the rear wake area. For the buffeting phenomenon, HSM has a hollow interior volume with sound absorption pads on its interior walls and a rectangular opening area on the upper surface. The panels $(12 \mathrm{~mm})$ and frames of the body are made of aluminium and the absorption pad is $20 \mathrm{~mm}$ thick, as Fig. 2.

The experimental study consisted of three steps. First, the acoustic response test(ART) was carried out to consider the damping effect of the interior model volume. Second, in order to validate basic prediction of flow field, velocity profiles were measured at three points on the upper part of the model using by a pitot tube array at $60 \mathrm{~km} / \mathrm{h}$ as shown in Fig. 3. Finally, the frequencies and sound pressure levels of buffeting were measured through a microphone positioned at the center of the interior volume at various wind speeds from $20 \mathrm{~km} / \mathrm{h}$ to $100 \mathrm{~km} / \mathrm{h}$.

All experiments were conducted in Hyundai aeroacoustic wind tunnel(HAWT). HAWT is a closed circuit type wind tunnel for aerodynamic and aeroacoustic measurement. Its maximun wind speed is $200 \mathrm{~km} / \mathrm{h}$ with a $28 \mathrm{~m}^{2}$ nozzle area and the level of the background noise is $56 \mathrm{dBA}$ at $100 \mathrm{~km} / \mathrm{h}$.

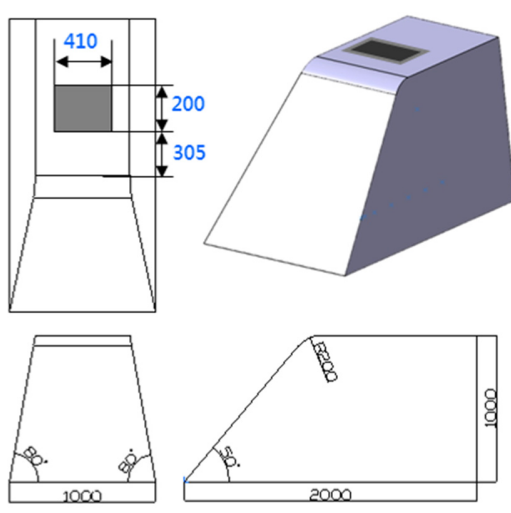

Fig. 2 Hyundai simplified model(HSM) 


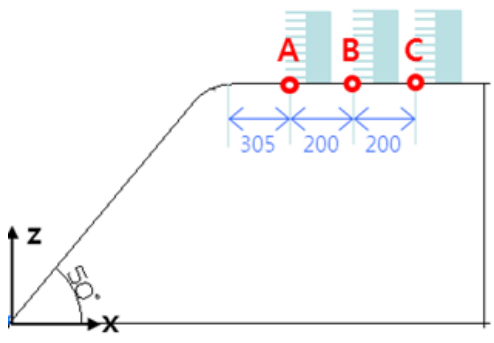

Fig. 3 Measurement points of velocity profiles

\subsection{Acoustic Response Test(ART)}

In order to consider the damping effect by the interior sound absorption material, one of the important real world effects, complex transfer functions, can be examined through the $\mathrm{ART}^{(1,2)}$.

As the acoustic excitation, a loud speaker was used to generate white noise of very high sound pressure level. According to the position of a response microphone, the acoustic response test was performed in two steps as shown in Fig. 4. The position of the reference microphone was fixed to the center point between the loud speaker and the upper surface of HSM. In the first step, the response microphone was located at the center of the interior volume of the model and the upper-side rectangular area was opened. When white noise was radiated, both the reference and response microphones received noise signals at the same time. In the second step, the upper opening area was closed, and the response microphone was located just above the upper surface of the model. In the same manner as in the first step, the sound pressure levels in the two microphones were measured simultaneously while under the radiation of white noise.

For each step, the complex transfer function $(c t f)$ is defined as

$$
c t f(f, g)=\frac{G_{k} F_{k}^{*}}{p s d_{k}(g)}
$$

where $g$ is signal of a reference microphone, $f$ is one of a response microphone, $G_{k}$ and $F_{k}$ are the

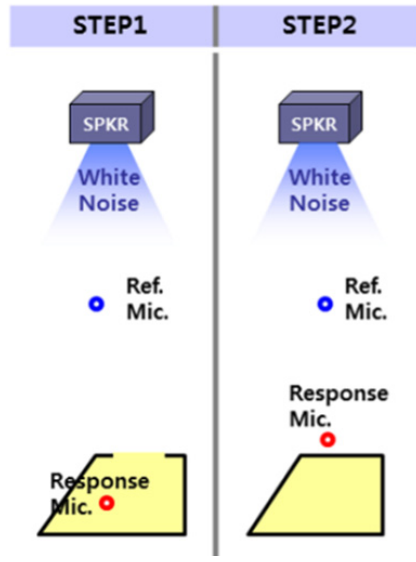

Fig. 4 Acoustic response test

Fourier transform of $g(t)$ and $f(t)$, the complex conjugate is denoted by '*' and psd means power spectral density.

The total complex transfer function of ART can be derived from complex transfer functions (ctf) of each step as

$$
H(\omega)=\frac{c t f_{1}}{c t f_{2}}
$$

From Eq. (2), the resonance frequency and Q-factor could be determined. "Q-factor" describes the characteristic of the damping effect of the whole system. Resonance frequency is the value of frequency when the phase angle is equal to $-\pi / 2$ in the complex transfer function. From the magnitude of the complex transfer function, the Q-factor can be obtained using the half-power bandwidth method as

$$
Q=\frac{\omega_{0}}{\omega_{2}-\omega_{1}}
$$

where the frequencies, $\omega_{0}, \omega_{1}$, and $\omega_{2}$ could be determined as shown in Fig. 5. In this test, the resonance frequency was $26.7 \mathrm{~Hz}$, and the Q-factor was 10.52 shown in Fig. 6.

The buffeting phenomena can be assumed as a Helmholtz resonator, resonance frequency and 


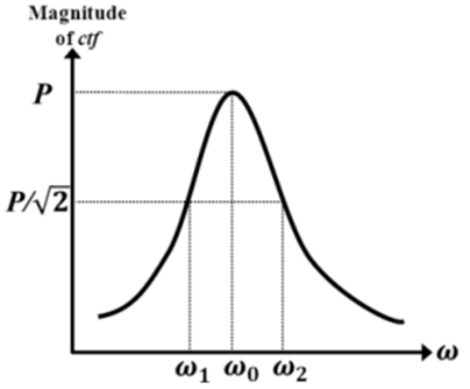

Fig. 5 Half-power bandwidth method

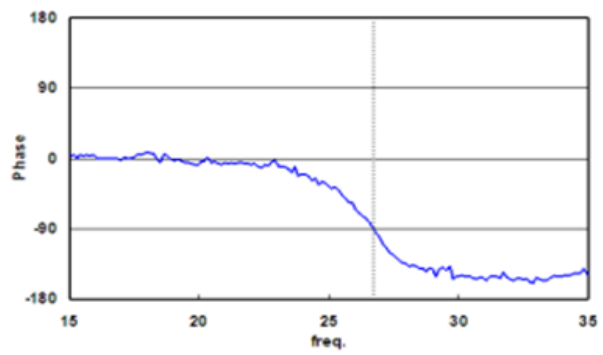

(a) Phase angle

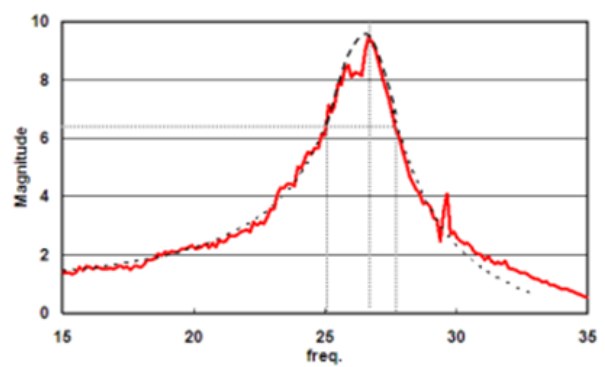

(b) Magnitude

Fig. 6 Complex transfer functions of the experimental ART

Q-factor can be calculated by acoustic theories ${ }^{(2)}$ as

$$
f_{r}=2 \pi c \sqrt{\frac{S}{L^{\prime} V}}, \quad Q=2 \pi \sqrt{V\left(\frac{L^{\prime}}{S}\right)^{3}}
$$

where $c$ is the speed of sound, $S$ is the neck area, $V$ is the cavity volume, $L$ is the neck length and $L^{\prime}$ is determined according to $L^{\prime}=L+$ $0.96 \cdot S^{1 / 2}$.

The theoretical values of the resonance frequency and Q-factor are $26.6 \mathrm{~Hz}$ and 48.6 respectively.

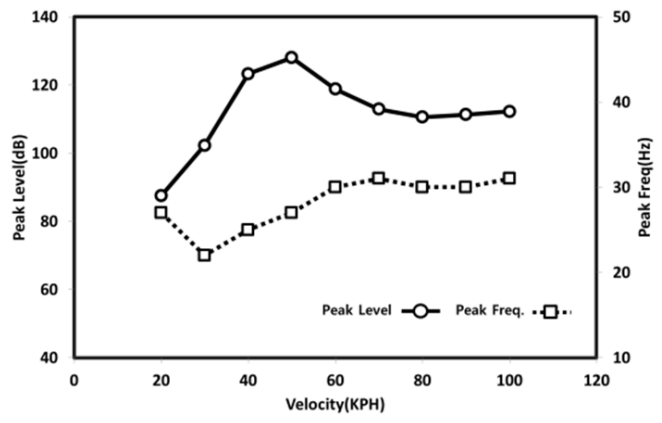

Fig. 7 Peak frequencies and peak sound pressure levels at each velocity from 20 to $100 \mathrm{~km} / \mathrm{h}$

The resonance frequencies from the theory and experimental data are quite similar. It can be shown that the maximum sound pressure of buffeting would be generated at the resonance frequency. The Q-factors are not as similar, the experimental value is significantly less than the theoretical one. This difference shows the damping effect caused by interior sound absorption materials. These values were provided to each solution maker prior to the numerical simulation in order to consider the real world effects of sound absorption materials.

\subsection{Buffeting Test}

In the buffeting test, peak frequencies and peak sound pressure levels were measured for a range of wind speeds from $20 \mathrm{~km} / \mathrm{h}$ to $100 \mathrm{~km} / \mathrm{h}$, as shown in Fig. 7. The peak sound pressure level had maximum value at $50 \mathrm{~km} / \mathrm{h}$ and the buffeting phenomena became weak at wind speeds over 80 $\mathrm{km} / \mathrm{h}$.

\section{Benchmark Study Results}

\subsection{Overview of CFD solvers}

Seven commercial solvers attended the benchmark test, which included a variety of software packages covered from world-wide CFD software providers to prototype code under development.

Each solver applied a variety of numerical 
Table 1 Summary of CFD sSolvers

\begin{tabular}{c|c|c|c|c|c|c|c}
\hline \hline Solver & $\mathrm{A}$ & $\mathrm{B}$ & $\mathrm{C}$ & $\mathrm{D}$ & $\mathrm{E}$ & $\mathrm{F}$ & $\mathrm{G}$ \\
\hline Numerical method & LBM & FVM & FVM & FEM & FVM & LBM & FDM \\
\hline Turbulent model & $\begin{array}{c}\text { VLES } \\
\text { (RNG) }\end{array}$ & DES SA & DDES & LES & $\begin{array}{c}\text { Cubic k-e } \\
\text { method }\end{array}$ & $\begin{array}{c}\text { Wall-Adapting } \\
\text { LES }\end{array}$ & $\begin{array}{c}\text { LES } \\
\text { Mesh size }\end{array}$ \\
\hline Time step(sec) & $1.28 \times 10^{-6}$ & $2.5 \times 10^{-5}$ & $1 \times 10^{-4}$ & $1 \times 10^{-4} \sim 1 \times 10^{-5}$ & $3 \times 10^{-4}$ & $1.7 \times 10^{-5}$ & $1.17 \times 10^{-6}$ \\
\hline Smallest cell size(mm) & 0.75 & 0.25 & 2 & 0.2 & 0.05 & $1.2 \mathrm{M}$ & 3 \\
\hline
\end{tabular}

methods and turbulence models that covered finite volume, element, difference method, and the lattice Boltzmann method as shown in Table 1.

\subsection{Validation of Velocity Profiles}

When the sunroof area on the upper surface was closed, the velocity profiles were measured at three points as shown in Fig. 3. The comparison of experimental and numerical results of each solver is shown in Fig. 8. Most solvers can predict the thickness of the boundary layer with enough accuracy, but the shapes of profiles are not matched well in any of the solvers. These discrepancies can introduce some errors into prediction of the buffeting behavior.

\subsection{Benchmark Results of Buffeting}

A comparison of measurements and numerical studies is shown in Fig. 9 and 10. At each velocity range from $20 \mathrm{~km} / \mathrm{h}$ to $100 \mathrm{~km} / \mathrm{h}$, the accuracy of each solver is validated.

The ability to predict peak sound pressure level can be examined by experimental data as shown in Fig. 9. In order to apply practical vehicle development process, computational prediction priority can be proposed like this: First, the velocity at the maximum level of sound pressure, second, the tendencies of sound pressure levels according to the velocities, and third, the quantities of peak sound pressure levels.

Solver $\mathrm{A}$ and $\mathrm{C}$ can predict the velocity of maximum SPL value, $50 \mathrm{~km} / \mathrm{h}$. Solver A, B, C and $\mathrm{D}$ can predict the tendencies of SPL. Solver B, C and E can make good agreement with experimental data under $50 \mathrm{~km} / \mathrm{h}$.

The capability to predict resonance frequencies was validated as shown in Fig. 10. Computational prediction priority can be proposed like this: First, the frequency at the maximum SPL value, second, the tendencies of frequencies according to the velocity and third, the quantities of resonance frequencies.

Solver A and C can predict the frequency of the maximum SPL value. Solver A and F can predict the tendencies of peak frequencies, in particular, the local decrease at $30 \mathrm{~km} / \mathrm{h}$. Solver A, $\mathrm{B}, \mathrm{C}$, and $\mathrm{E}$ can make good agreement with experiments. Solver ' $G$ ' could not show enough accuracy because it was still in development.

Every numerical study was performed without any of the results of buffeting tests except the wind tunnel test conditions and ART results. The results of ART were provided before the simulation in order to take the real world effects into consideration.

After this benchmark study, all the results were posted to every participating maker. Computational prediction priorities could be shared among CFD solution suppliers and commercial users. Each solver could be calibrated by the accurate wind tunnel test results. Therefore, the know-how of a computational approach for commercial vehicles 


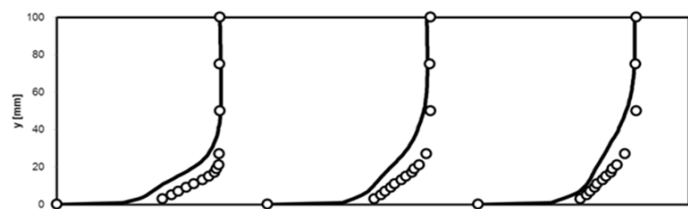

(a)

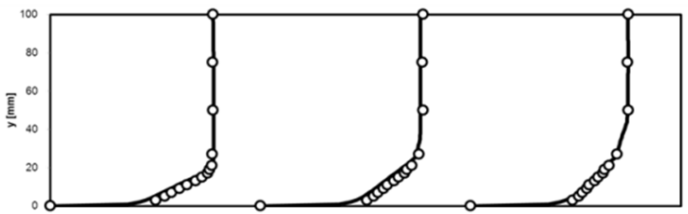

(b)

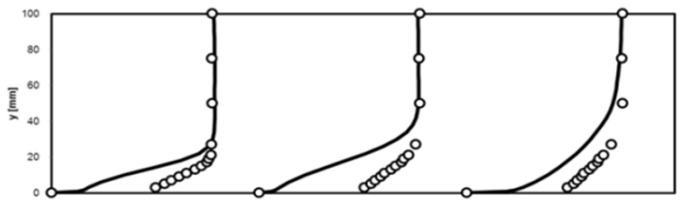

(c)

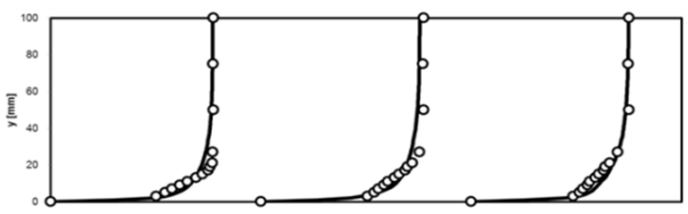

(d)

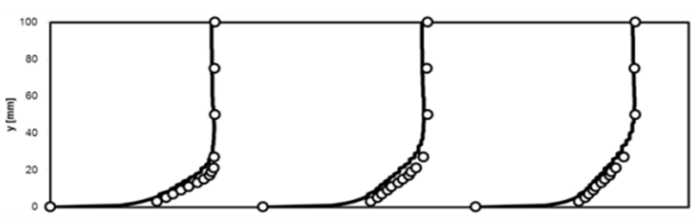

(e)

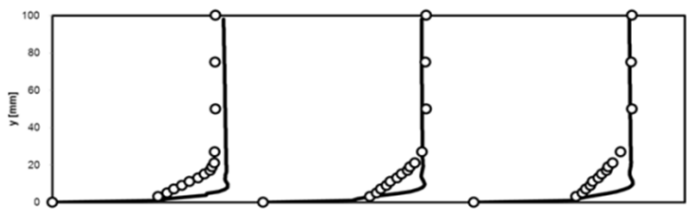

(f)

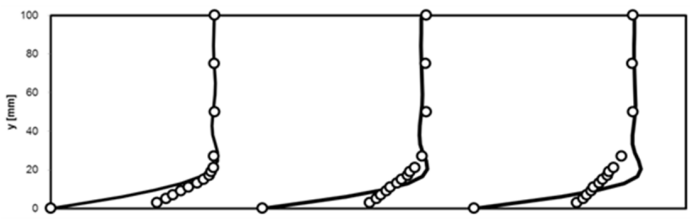

(g)

Fig. 8 Comparison of experimental and simulation results of velocity profiles of 7 solvers from 'A' to ' $G$ '
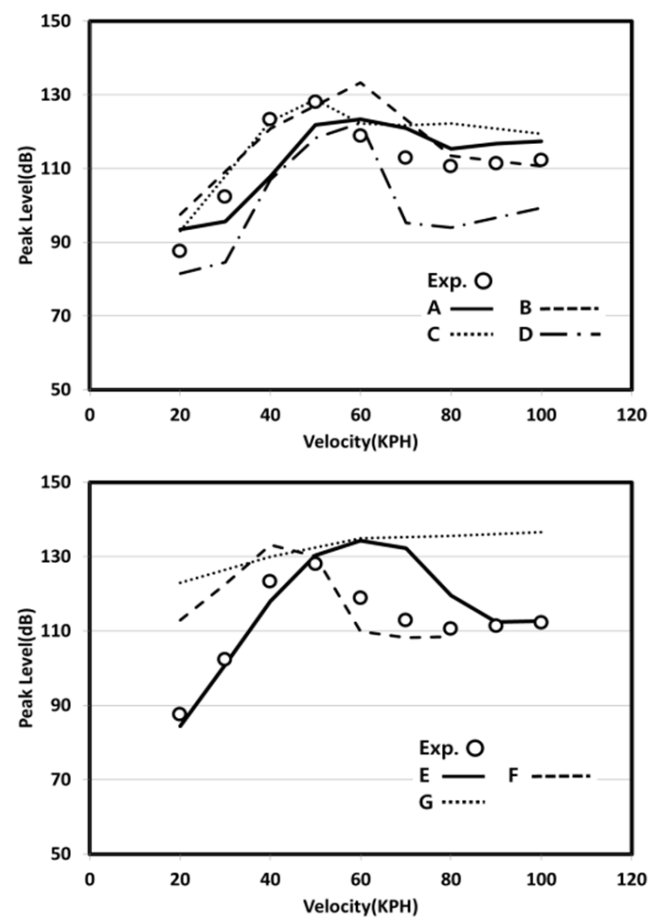

Fig. 9 Comparison of experimental and simulation results of peak sound pressure level(dB)
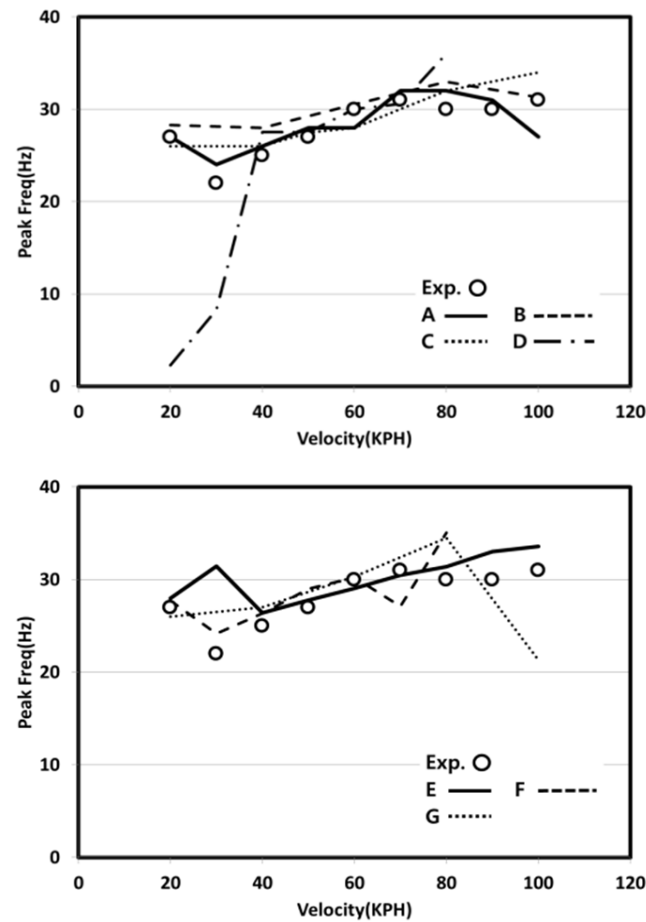

Fig. 10 Comparison of experimental and simulation results of peak frequency $(\mathrm{Hz})$ 

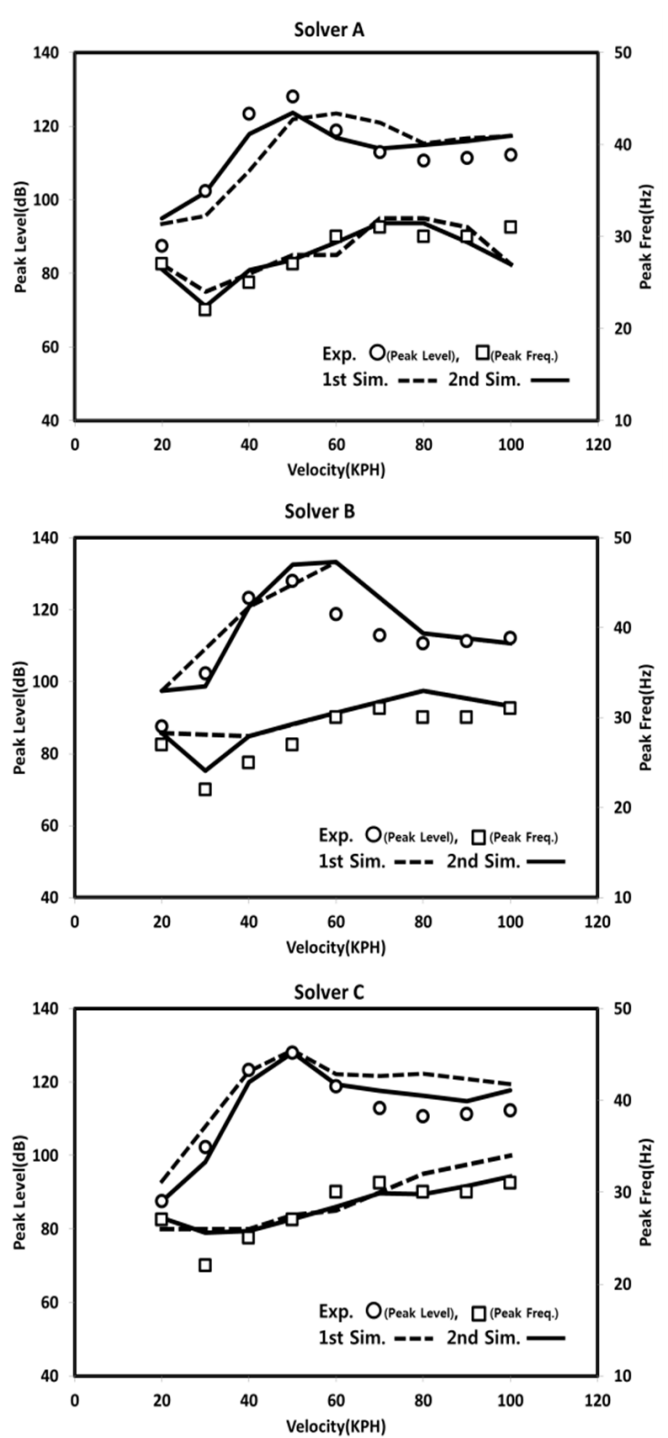

Fig. 11 Modified simulation results of solver A, B and $\mathrm{C}$

could be promoted and some of solvers could progress the accuracy level in the prediction of sunroof buffeting behaviors by modifying their simulation setup. As shown in Fig. 11, solver A can obtain much more accurate results from its second simulation than its first. It can be said that solver A can be well-calibrated with very high precision and show sufficient accuracy to apply real vehicle development with various real world effects. Solver B and C show the ability to pre- dict the velocity at maximum value of sound pressure level $(50 \mathrm{~km} / \mathrm{h})$ and the frequency at maximum SPL value with much better agreement with experimental results than their first numerical study.

\section{Conclusion}

The digital development of commercial vehicles can be crucial to the reduction of development time and costs. But accuracy issues should be overcome through the application of highly efficient simulations. To solve the issues, real world effects and prediction priorities should be considered. Therefore, this open benchmark study was conducted to minimize the issues.

As the main theme of this study, the prediction of the sunroof buffeting behaviors were presented, which has strong coupling of aerodynamics and aeroacoustics. To consider the real world effects, an acoustic response test(ART) was carried out and the results were attained before each solver carried out its simulation.

Seven solvers tried to simulate the acoustic behavior and some of them showed enough accuracy to apply to the process of commercial vehicle development. All of the results of each simulation were validated by high precision experimental measurements in a Hyundai aeroacoustic wind tunnel(HAWT). Almost all solvers could modify the errors of the first trial and get much more accurate results that should be described in the following papers. In this benchmark test, a variety of the CFD solvers could be calibrated to promote their accuracy level to the standard required in the actual process of road vehicle development.

\section{Acknowledgements}

The authors would like to thank ANSYS India \& Korea, CD-adapco, Cedic Co., ESI Korea, 
EXA, Flow\&Noise Inc. and Next Limit Technologies(listed in alphabetical order) for their supports of the numerical simulation.

\section{References}

(1) Crouse, B., Senthooran, S., Balasubramanian, G., Freed, D., Nölting, S., Mongeau, L. and Hong, J. S., 2005, Sunroof Buffeting of a Simplified Car Model: Simulations of the Acoustic and Flow-induced Responses, SAE Paper No. 2005-01-2498.

(2) Kinsler, L., Frey, A., Coppens, A. and Sanders, J., 2000, Fundamentals of Acoustics, 4th ed., John Wiley \& Sons Inc.

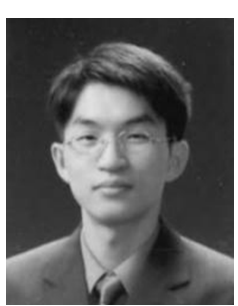

Munhwan Cho is a senior research engineer in $R \& D$ division of Hyundai Motor Group, who is in charge of development of sound and vibration of a road vehicle.

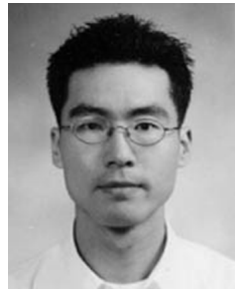

Hyoung Gun Kim is a senior research engineer in $R \& D$ division of Hyundai Motor Group, who is in charge of development of sound and vibration of a road vehicle. His recent research focus is to develop a virtual test system reproducing actual road driving conditions.

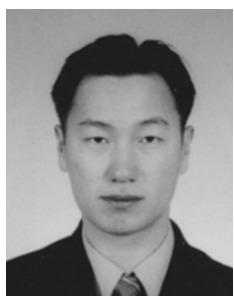

Chisung Oh is a senior research engineer in $R \& D$ division of Hyundai Motor Group, who is in charge of development of sound and vibration of a road vehicle, especially the noise reduction system by active noise control.

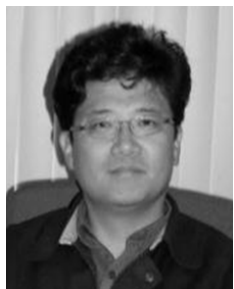

Kang-duck Ih is a NVH fellow in R\&D division of Hyundai Motor Group, whose research interest is covering a variety of phenomena related with sound and vibration in a road vehicle. 